\title{
COULD SUDDEN CARDIAC DEATH IN EPILEPSY BE RELATED TO THE OCCURRENCE OF THALAMIC DYSFUNCTION OR ANATOMIC CHANGE?
}

\author{
Fulvio A. Scorza', Lineu Calderazzo', Marly de Albuquerque', \\ Ricardo M. Arida ${ }^{2}$, Antonio-Carlos G. de Almeida ${ }^{3}$, Esper A. Cavalheiro'
}

\begin{abstract}
Sudden unexpected death in epilepsy (SUDEP) is the most important direct epilepsy-related cause of death in people with chronic epilepsy. Its physiopathology is still unknown; however, the most commonly suggested potential mechanisms involve cardiac or respiratory abnormalities. As the anatomical substrate of epileptic activity in the central nervous system (CNS) shows a direct relationship with cardiovascular alterations, this may suggests that patients with epilepsy associated with focal CNS lesions may be at particular risk of SUDEP. Currently, experimental and clinical data support an important role for thalamic nuclei in the behavioural manifestations, initiation and propagation of seizures. In view of the above findings, we purpose that SUDEP, at least in some cases, could be related to the occurrence of thalamic dysfunction or anatomic change.

KEY WORDS: epilepsy, cardiovascular abnormalities, heart, thalamus, sudden unexpected death in epilepsy.
\end{abstract}

\begin{abstract}
A morte súbita cardiaca em epilepsia poderia estar relacionada com a ocorrência de alterações anatômicas ou funcionais do tálamo?

Resumo - A morte súbita e inesperada nas epilepsias (SUDEP) é a mais importante causa de morte em pacientes com epilepsia. A fisiopatologia da SUDEP ainda é desconhecida, no entanto, os prováveis mecanismos estão relacionados com alterações cardiovasculares ou respiratórias. Como o substrato anatômico da atividade epiléptica no sistema nervoso central (SNC) apresenta direta relação com alterações cardiovasculares, esse fato sugere que pacientes com epilepsia e lesões focais no SNC podem apresentar maior risco para SUDEP. Atualmente, dados experimentais e clínicos demonstram um importante papel dos núcleos talâmicos nas manifestações comportamentais, bem como no início e propagação das crises epilépticas. Sendo assim, nós acreditamos que a SUDEP, pelo menos em alguns casos, poderia estar relacionada com a ocorrência de alterações anatômicas ou disfunções talâmicas.
\end{abstract}

PALAVRAS-CHAVE: epilepsia, alterações cardiovasculares, coração, tálamo, morte súbita e inesperada nas epilepsias.

\section{SUDDEN UNEXPECTED DEATH IN}

\section{EPILEPSY: GENERAL ASPECTS}

Epilepsy is the most common serious neurological condition. Approximately 50 million people worldwide have epilepsy'. In the US each year, about 100,000 new cases of epilepsy are diagnosed ${ }^{2,3}$. In the UK between 1 in 140 and 1 in 200 people (at least 300,000 people) are currently being treated for epilepsy ${ }^{4}$. Epidemiological studies suggest that between 70 and $80 \%$ of people developing epilepsy will go into remission, while the remaining patients continue to have seizures and are refractory to treatment with the currently available therapies ${ }^{5,6}$. The most common risk factors for epilepsy are cerebrovascular diseases, brain tumours, alcohol, traumatic head injuries, malformations of cortical development, genetic inheritance and infections of the central nervous system ${ }^{7}$. In resource-poor countries, endemic infections, such as malaria and neurocysticercosis seem to be major risk factors ${ }^{8}$.

Sudden unexpected death in epilepsy (SUDEP) is defined as sudden, unexpected, witnessed or unwitnessed, nontraumatic and nondrowning deaths in patients with epilepsy, with or without evidence of a seizure and excluding documented status epilepticus, in which post mortem examination does not reveal a toxicological or anatomi-

'Disciplina de Neurologia Experimental, Universidade Federal de São Paulo/Escola Paulista de Medicina, São Paulo SP, Brasil (UNIFESP/EPM); ${ }^{2}$ Departamento de Fisiologia, UNIFESP/EPM; 'Departamento de Engenharia Biomédica, Universidade Federal de São João Del Rei, São João Del Rei MG, Brasil (UFSJ).

Received 7 August 2008, received in final form 30 September 2008. Accepted 11 November 2008.

Dr. Fulvio Alexandre Scorza - Disciplina de Neurologia Experimental - Rua Botucatu 862 -04023-900 São Paulo SP - Brasil. E-mail: scorza.nexp@epm.br 
cal cause of death 9 . Comparisons of incidence estimates for SUDEP are difficult as different definitions of SUDEP have been used, not all patients have postmortem examination, case ascertainment methods and source populations have varied ${ }^{10}$. The incidence of SUDEP has been estimated as $3.5 / 1000$ person-years in a lamotrigine clinical trial ${ }^{11}, 0.5-1.4 / 1000$ person-years in people with treated epilepsy ${ }^{12}, 5.9 / 1000$ person-years in outpatients with epilepsy at a tertiary referral center ${ }^{13}, 9 / 1000$ personyears in candidates for epilepsy surgery and $0.35 / 1000$ person-years in a population-based study ${ }^{14}$. The National General Practice Study of Epilepsy (NGPSE) a community-based study in the United Kingdom has seen the first case of SUDEP after 11,000 person-years of follow-up in ${ }^{15}$ and the results of the Medical Research Council Antiepileptic Drug Withdrawal Study showed that SUDEP among patients with epilepsy in remission is a rare event ${ }^{16}$. Information concerning risk factors for SUDEP is conflicting, but potential risk factors include: age ${ }^{11}$, early onset of epilepsy ${ }^{17}$, duration of epilepsy ${ }^{18}$, uncontrolled seizures, mainly temporal lobe epilepsy (TLE) ${ }^{18,19}$, seizure frequency ${ }^{18-20}$, seizure type ${ }^{18,20,21}$, anti-epileptic drugs (AED) number ${ }^{1718,22}$ and winter temperatures ${ }^{23}$. Additionally, potential pathomechanisms for SUDEP, including pathological changes in the heart, cardiac arrhythmia during and between seizures, electrolyte disturbances, arrhythmogenic drugs or transmission of epileptic activity via the autonomic nervous system to the heart have been extensively investigated (for review $\mathrm{see}^{24}$ ). Overall, in all studies the risk of sudden death in epilepsy is found to be elevated. Clarification of risk factors and establishment of the mechanisms of SUDEP are important so that as many people as possible can be saved from SUDEP.

\section{CARDIAC CHANGES INDUCED BY STIMULATION OR LESION OF SOME CENTRAL NERVOUS SYSTEM STRUCTURES IN THE HEALTHY BRAIN}

It has long been believed that, in the healthy brain, stimulation (or lesion) of some central nervous system (CNS) structures is able to promote morphological and functional cardiovascular alterations. Earlier studies have shown that electrical stimulation of the hypothalamus can lead to autonomic cardiovascular disturbances ${ }^{25}$ and that hypothalamic lesions can lead to cardiac and gastrointestinal haemorrhages ${ }^{26}$. A variety of stresses applied to cortico-preconditioned rats succeeded in producing a common type of cardiac necrosis ${ }^{27}$. Moreover stimulation of certain brain areas (subiculum, posterior hypothalamus, ventrolateral thalamus and substantia nigra) has been shown to modify heart function without producing disturbances in the activity of the brain ${ }^{28}$. In addition, other workers showed that injections of a small dose of picrotoxin into the lateral ventricle of rabbits and cats leads to a rise in blood pressure associated with various types of ischaemic-like electrocardiographic changes and arrhythmias $^{29}$. In the same year, it was reported that electrical stimulation of the cortex of the left frontal lobe in cats leads to constriction of the coronary blood vessels associated with ischaemic changes in the $\mathrm{ECG}^{30}$. Other workers brought about myocardial necrosis by exposing wild rats to tape recorded cat-rat fights and showed that anti-adrenergic drugs protected rats from stress-induced cardiac damage $e^{31}$. It has also been reported that angiotensin II, when administered into the lateral ventricle of cats, is able to induce a severe tachycardia ${ }^{32,33}$. Coronary hyperaemia, ventricular tachycardia with chaotic heart activity and evoked marked elevations of blood pressure could be observed when unipolar stimulations of various brain regions of dogs were evaluated ${ }^{34}$. Moreover, electrical stimulation of the stellate ganglion in dogs produced focal myocardial necrosis ${ }^{35}$. Lateral septal lesions have been shown to enhance conditioned bradycardia in the rabbit, suggesting that septo-hippocampal circuits participate in classical conditioning of cardiovascular changes $^{36}$. In 1985, it was also shown that electrical stimulation of insular cortex elicits cardiac inhibition but insular lesions do not abolish conditioned bradycardia in rabbits ${ }^{37}$. In parallel, the role of the insular cortex on cardiovascular changes was confirmed in human studies ${ }^{38}$. Acute chemical lesions of the dorsal periaqueductal gray (DPAG) have been shown to produce a reduction in resting arterial pressure accompanied by an increase in heart rate in conscious rats ${ }^{39}$, suggesting that DPAG is involved in the tonic and reflex control of resting arterial pressure and heart rate. More recently, a marked tachycardia immediately after a lesion of the anteroventral third ventricle of rats was demonstrated ${ }^{40}$.

\section{A POSSIBLE ROLE OF THE THALAMUS IN SUDDEN UNEXPECTED DEATH IN EPILEPSY}

SUDEP is the most important direct epilepsy-related cause of death in people with epilepsy. Its cause is still unknown; however, the most commonly suggested mechanisms involve cardiac. As the anatomical substrate of epileptic activity in the CNS shows a direct relationship with cardiovascular alterations, this may suggests that patients with epilepsy associated with focal CNS lesions may be at particular risk of SUDEP ${ }^{10,41}$. It has been shown that epileptic activity originating in the amygdala, cingulated gyrus, insular cortex, frontopolar or frontoorbital regions may induces arrhythmias (such as supraventricular tachycardia), sinus tachycardia, sinus bradycardia, sinus arrest, atrioventricular block and asystole $e^{42}$, which could be implicated in SUDEP.

Currently, experimental and clinical data support an important role for thalamic nuclei in the behavioural 

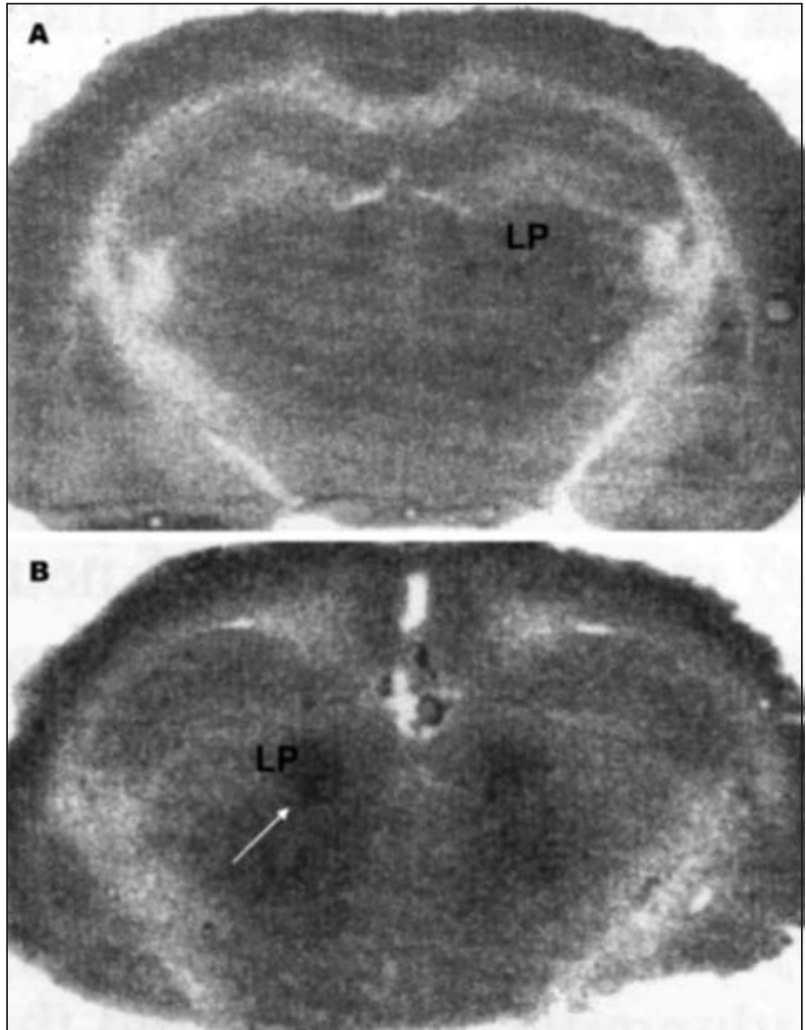

Fig 1. Representative $\left[{ }^{14} \mathrm{C}\right] 2 \mathrm{DG}$ autoradiographs of the lateral posterior thalamic nuclei (LP). (A) $\left[{ }^{14} C\right] 2 D G$ autoradiographs prepared from control animals. (B) $\left[{ }^{14} C\right] 2 D G$ autoradiographs prepared from animals with epilepsy. Note the activation of the LP (arrow).

manifestations, initiation and propagation of epileptic seizures ${ }^{43}$, although the possible role of thalamic nuclei in triggering and spreading epileptic discharges has been discussed over the last four decades ${ }^{44}$. The importance of the thalamus in the genesis of epileptic seizures correlates with its extensive projection to the cortex and other areas, including the basal ganglia, cerebellum, and hippocampus ${ }^{45,46}$. Whilst TLE is the most common form of partial epilepsy, and hippocampal atrophy and sclerosis are the most frequent abnormalities associated with TLE, brain structural changes in patients with TLE are not confined solely to the hippocampus. Indeed, they have been reported to occur in other brain regions, such as the parahippocampal region, entorhinal and perirhinal cortex ${ }^{47-49}$. Interestingly, a recent study demonstrated thalamic atrophy in patients with TLE, which was more prominent in the thalamic nuclei that have strong connections with the limbic system ${ }^{50}$. Moreover, using the pilocarpine model of temporal lobe of epilepsy, our research group has also reported an important role of the posterior thalamus in the cerebral circuits of rats with epilepsy. The first study investigating the interictal cerebral metabolic rate by 14C-2DG autoradiography in chronic pilocarpineinduced rats, found an increase in glucose utilization by

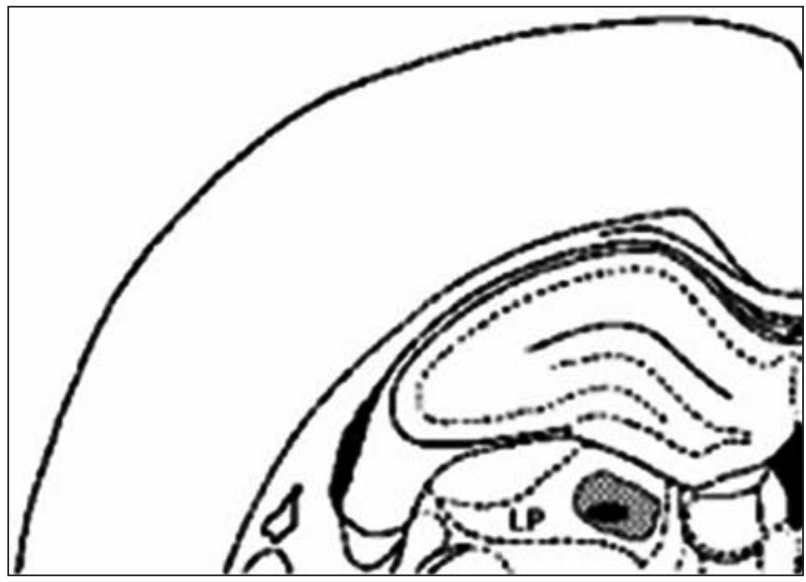

Fig 2. Diagrammatic representation of the extent of the lesioned area following ibotenic acid injection in the lateral posterior thalamic nuclei (LP). The hatched area represent the larger lesion while black area depict the smaller lesion.

several epileptic brain regions ${ }^{51}$. The most relevant finding was a consistent rise of cerebral metabolic rate in the lateral posterior thalamic nuclei (LP), suggesting that the LP may be involved in the cerebral circuitry controlling epileptic activity during interictal intervals (Fig 1). The second study evaluated the contribution of LP to spontaneous recurrent seizure activity induced by pilocarpine ${ }^{52}$. It was shown in this study that bilateral LP lesion by ibotenic acid in chronic epileptic rats (Fig 2) resulted in an increase of seizure frequency, suggesting that LP is one of the most important thalamic nuclei involved in the inhibition of spreading mechanisms (Fig 3). Moreover, subtle thalamic structural abnormalities are also present in patients with generalized idiopathic epilepsies as revealed by MRI volumetric and voxel-based morphometry studies ${ }^{53,54}$.

In accordance to the above mentioned findings, it seems plausible to propose that cardiovascular abnormalities and hence SUDEP, at least in some cases, could be related to the occurrence of lateral posterior thalamic morphological or functional changes. As research in this field must be guided by the possible mechanism of SUDEP, a number of arguments might be put forward.

From a morphological point of view, Boyko and coleagues ${ }^{55}$ showed that bilateral injections of kainic acid into the thalamus, mainly in the lateral posterior thalamic nuclei, produced myocardial necrosis in adult rats, suggesting that this specific thalamic nucleus has a direct relationship with cardiovascular system. In the same way, it is very important to establish if there is a relation between lateral posterior thalamic nuclei dysfunction and cardiac functioning. According with this reasoning, an experimental study developed by our group could better start to reinforce this idea. In 2005, we evaluated the heart rate, in vivo (ECG) and isolated ex vivo preparation (Langendorf preparation) of rats with epilepsy ${ }^{56}$. Our results showed 


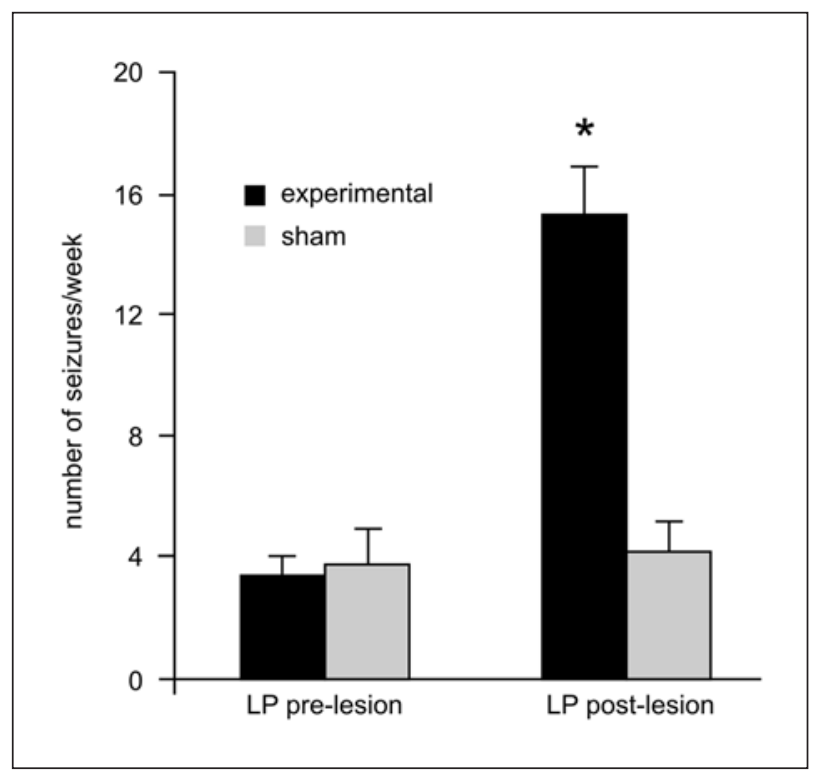

Fig 3. Graphic representation of the cumulative frequency of spontaneous seizures per week detected in sham and experimental groups, before and after saline or ibotenic acid injections into lateral posterior thalamic nuclei (LP). Data are expressed as mean $\pm S D$. ${ }^{*} p<0.05$.

significant differences in the mean of heart rate in vivo between the groups (control animals: $307 \pm 9$ bpm; animals with epilepsy: $346 \pm 7 \mathrm{bpm})$. In contrast, we did not find differences during isolated ex vivo situation (control animals: $175 \pm 7$ bpm; animals with epilepsy: 176 \pm 6 bpm), suggesting a central nervous system modulation on the heart (such as thalamic nucleus), which could explain the sudden unexpected death in epilepsy (Fig 4). Quite interesting and more recently, our group (Scorza and colleagues, unpublished data) evaluated the heart rate (in vivo and isolated ex vivo) of rats with epilepsy before and after bilateral LP lesion. The results showed significant differences in the mean heart rate in vivo, but surprisingly, no differences in heart rate could be observed in the isolated ex vivo situation. These observations seem to indicate a certain kind of specific thalamic modulation over the heart functioning what could support our hypothesis of SUDEP due to heart failure in consequence of thalamic dysfunction.

In summary, we would like to raise the possibility that the presence of thalamic nuclei lesions in people with TLE could underlie some processes that culminates in SUDEP and that heart failure could have a significant role in this mechanism. However, a clear relationship between TLE, thalamic dysfunction, heart failure and SUDEP still needs to be demonstrated both in experimental and human conditions. In the meantime, strategies, such as taking a detailed cardiovascular history, looking for cardiovascular co-morbidity, cardiovascular risk factors and prior cardiac findings (electrocardiogram and echocardiogram), should be developed in an attempt to prevent SUDEP.

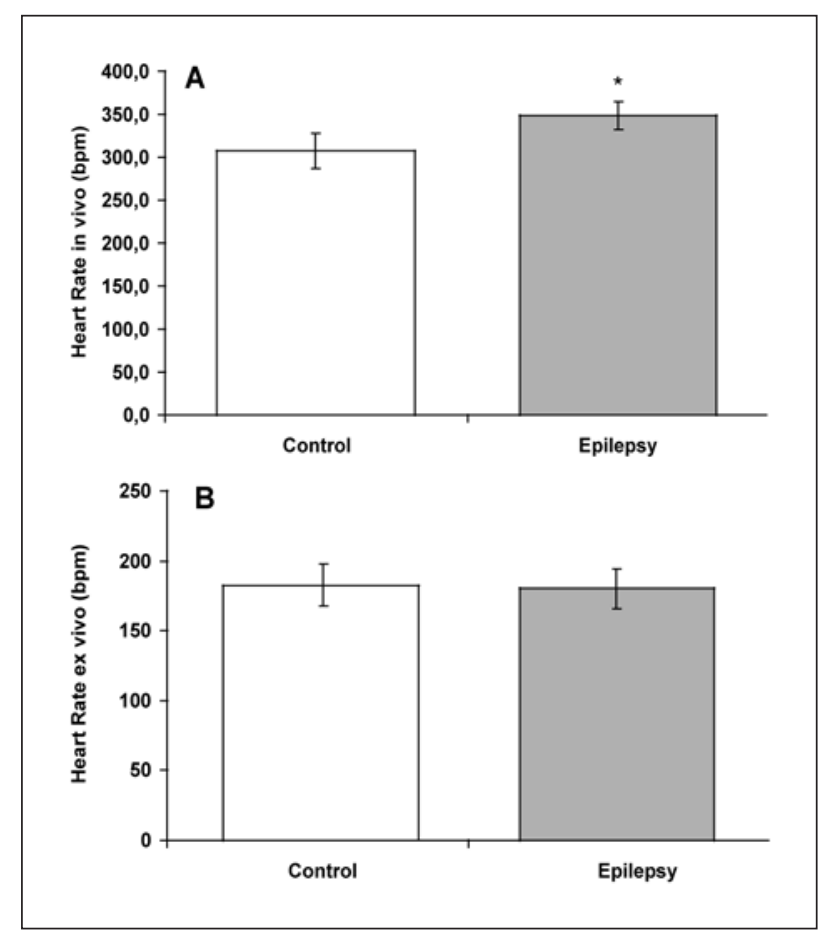

Fig 4. Mean and standard deviation of heart rates of control rats and rats with epilepsy obtained during in vivo (A) and isolated ex vivo situation (B).

\section{REFERENCES}

1. Sander JW. The epidemiology of epilepsy revisited. Curr Opin Neurol 2003; 16:165-170.

2. Annegers JF. Epidemiology of epilepsy. In: Wyllie E (ed). The treatment of epilepsy: principles and practice. 2nd ed. Baltimore: Williams \& Wilkins, 1997:165-172.

3. Begley CE, Annegers JF, Lairson LB, Reynolds TF. Epilepsy incidence, prognosis, and use of medical care in Houston, Texas, and Rochester, Minnesota. Epilepsia 1998;39:222.

4. Yuen AW, Sander JW. Is omega-3 fatty acid deficiency a factor contributing to refractory seizures and SUDEP? A hypothesis. Seizure 2004;13:104-107.

5. Sander JW. Some aspects of prognosis in the epilepsies: a review. Epilepsia 1993;34:1007-1016.

6. Kwan P, Sander JW. The natural history of epilepsy: an epidemiological view. J Neurol Neurosurg Psychiatry 2004;75:1376-1381.

7. Halatchev VN. Epidemiology of epilepsy-recent achievements and future. Folia Medica 2000;42:17-22.

8. Duncan JS, Sander JW, Sisodiya SM, Walker MC. Adult epilepsy. Lancet 2006;367:1087-1100.

9. Nashef L. Sudden unexpected death in epilepsy: terminology and definitions. Epilepsia 1997;38:S6-8.

10. Tomson T, Walczak T, Sillanpaa M, Sander JW. Sudden unexpected death in epilepsy: a review of incidence and risk factors. Epilepsia 2005;46:54-61.

11. Leestma JE, Annegers JF, Brodie MJ et al. Sudden unexplained death in epilepsy: observations from a large clinical development program. Epilepsia 1997;38:47-55.

12. Tennis P, Cole TB, Annegers JF, Leestma JE, McNutt M, Rajput A. Cohort study of incidence of sudden unexplained death in persons with seizure disorder treated with antiepileptic drugs in Saskatchewan, Canada. Epilepsia 1995;36:29-36.

13. Nashef L, Fish DR, Sander JW, Shorvon SD. Incidence of sudden unexpected death in an adult outpatient cohort with epilepsy at a tertiary referral centre. J Neurol Neurosurg Psychiatry 1995;58:462-464.

14. Ficker DM, So EL, Shen WK, et al. Population-based study of the incidence of sudden unexplained death in epilepsy. Neurology 1998;515:1270-1274.

15. Lhatoo SD, Johnson AL, Goodridge DM, MacDonald BK, Sander JW, 
Shorvon SD. Mortality in epilepsy in the first 11 to 14 years after diagnosis: multivariate analysis of a long-term, prospective, populationbased cohort. Ann Neurol 2001;49:336-344.

16. Medical Research Council. Antiepileptic Drug Withdrawal Study Group. Randomised study of antiepileptic drug withdrawal in patients in remission. Lancet 1991;337:1175-1180.

17. Nilsson L, Farahmand BY, Persson PG, Thiblin I, Tomson T. Risk factors for sudden unexpected death in epilepsy: a case-control study. Lancet 1999;353:888-893

18. Walczak TS, Leppik IE, $\mathrm{D}^{\prime}$ Amelio $\mathrm{M}$ et al. Incidence and risk factors in sudden unexpected death in epilepsy: a prospective cohort study. Neurology 2001;56:519-525.

19. Sperling MR, Feldman H, Kinman J, Liporace JD, O'Connor MJ. Seizure control and mortality in epilepsy. Ann Neurol 1999;46:45-50.

20. Langan Y, Nashef L, Sander JW. Case-control study of SUDEP. Neurology 2005;64:1131-1133.

21. Kloster R, Engelskjon T. Sudden unexpected death in epilepsy (SUDEP): a clinical perspective and a search for risk factors. J Neurol Neurosurg Psychiatry 1999;67:439-444.

22. Nilsson L, Bergman U, Diwan V, Farahmand BY, Persson PG, Tomson T. Antiepileptic drug therapy and its management in sudden unexpected death in epilepsy: a case-control study. Epilepsia 2001;42:667-673.

23. Scorza FA, de Albuquerque M, Arida RM, Cavalheiro EA. Sudden unexpected death in epilepsy: are winter temperatures a new potential risk factor? Epilepsy Behav 2007;10:509-510.

24. Stollberger C, Finsterer J. Cardiorespiratory findings in sudden unexplained/unexpected death in epilepsy (SUDEP). Epilepsy Res 2004;59:51-60.

25. Wang GH. Johann Paul Karplus (1866-1936) and Alois Kreidl (18641928): two pioneers in the study of central mechanisms of vegetative function. Buu Hist Med 1965;39:529-539.

26. Burdenko N, Mogilnitzki BZ. Zur pathogenese einiger Formen dês Runden-Magen-Darm geschwürs. Ztschr ges Neurol Psychiat 1926;103:42.

27. Selye H. The chemical prevention of cardiac necrosis. New York. Ronald Press, 1958

28. Delgado JM. Circulatory effects of cortical stimulation. Physiol Rev 1960;4:146-178

29. Melville KI, Garvey HL, Shister HE, Knaack J. Central nervous system stimulation and cardiac ischemic changes in monkeys. Ann N Y Acad Sci 1969;156:241-260.

30. Kisin IE, Sinitsyn LN. Prevention of disorders of myocardial blood supply, caused by the stimulation of the cerebral cortex by pharmacologic agents. Vestn Akad Med Nauk 1963;18:18-23.

31. Raab W, Chaplin Jp, Bajusz E. Myocardial necroses produced in domesticated rats and in wild rats by sensory and emotional stresses. Proc Soc Exp Biol Med 1964;116:665-669.

32. Smookler HH, Severs WB, Kinnard WJ, Buckley JP. Centrally mediated cardiovascular effects of angiotensin II. J Pharmacol Exp Ther 1966;153:485-494.

33. Severs WB, Daniels AE, Smookler HH, Kinnard WJ, Buckley JP. Interrelationship between angiotensin II and the sympathetic nervous system. J Pharmacol Exp Ther 1966;153:530-537.

34. Carroll MN Jr, Golinko RJ, Lyon AF, Dunst M, Rene HF Jr, Ford DH. CNS-evoked coronary changes and cardiac arrhythmias-anti-arrhythmic properties of mebutamate. Arch Int Pharmacodyn Ther 1968;171:462-474.

35. Klouda MA, Brynjolfsson G. Cardiotoxic effects of electrical stimulation of the stellate ganglia. Ann N Y Acad Sci 1969;156:271-280.
36. Powell DA, Milligan WL, Mull P. Lateral septal lesions enhance conditioned bradycardia in the rabbit. J Comp Physiol Psychol 1982;96:742-754.

37. Powell DA, Buchanan S, Hernandez L. Electrical stimulation of insular cortex elicits cardiac inhibition but insular lesions do not abolish conditioned bradycardia in rabbits. Behav Brain Res 1985;17:125-144.

38. Oppenheimer SM, Gelb A, Girvin JP, Hachinski VC. Cardiovascular effects of human insular cortex stimulation. Neurology 1992;42:1727-1732.

39. Sampaio KN, Mauad H, Biancardi VC, et al. Cardiovascular changes following acute and chronic chemical lesions of the dorsal periaqueductal gray in conscious rats. J Auton Nerv Syst 1999;76:99-107.

40. Pedrino GR, Nakagawa Sera CT, Cravo SL, Colombari DS. Anteroventral third ventricle lesions impair cardiovascular responses to intravenous hypertonic saline infusion. Auton Neurosci 2005;117:9-16.

41. Leestma JE, Walczak T, Hughes JR, Kalelkar MB, Teas SS. A prospective study on sudden unexpected death in epilepsy. Ann Neurol 1989;26: 195-203.

42. Devinsky O, Pacia S, Tatambhotla G. Bradycardia and asystole induced by partial seizures: a case report and literature review. Neurology 1997;48:1712-1714.

43. Norden AD, Blumenfeld $\mathrm{H}$. The role of subcortical structures in human epilepsy. Epilepsy Behav 2002;3:219-231

44. Jasper HH, Droogleever-Fortuyn J. Experimental studies on the functional anatomy of pett mal epilepsy. Res Publ Ass Nerv Ment Dis 1947;26:272-298.

45. Macchi G, Bentivoglio M, Minciacchi D, Molinari. Trends in the anatomical organization and functional significance of the mammalian thalamus. Ital J Neurol Sci 1996;17:105-129.

46. Faull RLM, Mehler WR. Thalamus. In: Paxinos G (ed.). The rat nervous system. Vol 1: Forebrain and midbrain. Sydney: Academic Press Australia, 1985:129-168.

47. Bonilha L, Kobayashi E, Rorden C, Cendes F, Li LM. Medial temporal lobe atrophy in patients with refractory temporal lobe epilepsy. J Neurol Neurosurg Psychiatry 2003;74:1627-1630.

48. Bonilha L, Kobayashi E, Cendes F, Min Li L. Protocol for volumetric segmentation of medial temporal structures using high-resolution 3-D magnetic resonance imaging. Hum Brain Mapp 2004;22:145-154.

49. Bernasconi N, Bernasconi A, Caramanos Z, Andermann F, Dubeau F, Arnold DL. Morphometric MRI analysis of the parahippocampal region in temporal lobe epilepsy. Ann N Y Acad Sci 2000;911:495-500.

50. Bonilha L, Rorden C, Castellano G, Cendes F, Li LM. Voxel-based morphometry of the thalamus in patients with refractory medial temporal lobe epilepsy. Neuroimage 2005;25:1016-1021.

51. Scorza FA, Sanabria ERG, Calderazzo L, Cavalheiro EA. Glucose utilization during interictal intervals in an epilepsy model induced by pilocarpine: a qualitative study. Epilepsia 1998;39:1041-1045.

52. Scorza FA, Arida RM, Priel M, Calderazzo L, Cavalheiro EA. The contribution of the lateral posterior and anteroventral thalamic nuclei on spontaneous recurrent seizures in the pilocarpine model of epilepsy. Arq Neuropsiquiatr 2002;60:572-575.

53. Betting LE, Mory SB, Li LM, Lopes-Cendes I, Guerreiro MM, Guerreiro CA, Cendes F. Voxel-based morphometry in patients with idiopathic generalized epilepsies. Neuroimage 2006;32:498-502.

54. Betting LE, Mory SB, Lopes-Cendes I, Li LM, Guerreiro MM, Guerreiro CA, Cendes F. MRI volumetry shows increased anterior thalamic volumes in patients with absence seizures. Epilepsy Behav 2006;8:575-580.

55. Boyko WJ, Galabru CK, McGeer EG, McGeer PL. Thalamic injections of kainic acid produce myocardial necrosis. Life Sci 1979;25:87-98.

56. Colugnati DB, Gomes PA, Arida RM, et al. Analysis of cardiac parameters in animals with epilepsy: possible cause of sudden death? Arq Neuropsiquiatr 2005;63:1035-1041. 